\title{
Desenvolvimento de Aplicativo AulaLeve para Formação de Professores em uma Metodologia de Aprendizagem Ativa
}

\author{
Fábio Cantergiani Ribeiro Mendes ${ }^{1}$, Marie Jane Soares Carvalho ${ }^{2}$ \\ ${ }^{1}$ Instituto Federal Sul-rio-grandense (IFSul), Gravataí - RS - Brasil \\ PGIE - Programa de pós-graduação em Informática na Educação, Universidade \\ Federal do Rio Grande do Sul (UFRGS), Porto Alegre - RS - Brasil \\ ${ }^{2}$ PGIE - Programa de pós-graduação em Informática na Educação, Universidade \\ Federal do Rio Grande do Sul (UFRGS), Porto Alegre - RS - Brasil \\ fabiomendesdifsul.edu.br, marie.janedufrgs.br
}

\begin{abstract}
The educational scenario requires a transition to new ways of teaching, with emphasis on active learning methodologies. This article presents the development and evaluation of an app for teacher training in Study Workshops, an active learning didactic that does not require access to technological resources in schools. The functionalities of the app are presented, followed by the results of an extension course for teachers and the data they have collected from their students. It was concluded that the website achieved results above expectations and that future research should reveal the impact of its massive use.
\end{abstract}

Resumo: O cenário educacional requer uma transição para novas formas de ensinar, com destaque para metodologias de aprendizagem ativa. $O$ presente artigo apresenta o desenvolvimento e avaliação de um aplicativo para formação de professores em Oficinas de Estudo, uma didática de aprendizagem ativa que não requer acesso a recursos tecnológicos nas escolas. As funcionalidades do aplicativo são apresentadas, seguidas dos resultados de um curso de extensão para professores e dos dados por eles colhidos com seus alunos. Conclui-se que o site atingiu resultados acima das expectativas que futuras pesquisas devem revelar o impacto de sua massificação.

\section{Introdução}

Todos concordam sobre a necessidade de alavancar a Educação no Brasil (UNICEF, 2014). Apesar de estarmos entre as maiores economias do mundo, somos apenas o $60^{\circ}$ colocado no ranking da Unesco na área da Educação (OECD, 2014), o que é pouco para uma país que ainda possui o desafio de diminuir suas desigualdades sociais (Arnould, 2014). Faz-se necessário, mesmo urgente, incrementar o serviço educacional em geral, o que engloba, certamente, melhorar a estrutura física das escolas, mas também qualificar o trabalho realizado por nossos educadores e gestores (OECD, 2015). A formação de professores é central para vencer essas dificuldades e iniciativas promissoras têm sido desenvolvidas para facilitar a gestão desse processo (Carvalho \& Neves e Melo, 2016). Diante das novas tecnologias na área de informática e comunicação, parece evidente a oportunidade de utilizar essas novas ferramentas para alavancar a educação (Foresti \& 
VIII Congresso Brasileiro de Informática na Educação (CBIE 2019)

Anais do XXX Simpósio Brasileiro de Informática na Educação (SBIE 2019)

Teixeira, 2012). Entretanto, a pergunta ainda permanece, porque a posse de ferramentas, sejam quais forem, só tem valia se soubermos como utilizá-las. Além disso, os desafios de nossa Educação são complexos e variados: é difícil acreditar que as novas tecnologias possam ser a solução de todas as dificuldades enfrentadas no setor (Gesser, 2012).

É preciso compreender a peculiaridade do cenário atual. Nunca o ser humano viveu em uma era de tanta incerteza. Não faz mais sentido, hoje, projetar que os próximos 20 anos serão semelhantes aos anteriores, seja do ponto de vista pessoal ou profissional: criam-se novas possibilidades de lazer, comunicação e uso do tempo em uma velocidade tal que não se consegue assimilar que tipo de impacto elas têm, positivos ou negativos (Bauman, 2007). Todos acompanham a revolução causada pela internet e os diferentes dispositivos que praticamente, universalizaram seu acesso. Contudo, revoluções similares são esperadas para as áreas da biotecnologia e energia, dentre outras. Em relação à Educação, tais mudanças precisam ser observadas e, então, consideradas como candidatas a serem incorporadas ao currículo (Morin, Ciurana \& Motta, 2007). A formação de professores, e a avaliação, estão em xeque (Perrenoud, 2007). Entretanto, o ponto, justamente, é que, à medida que surgem novos conteúdos e desafios, nenhuma atualização curricular será suficiente para dar conta, de fato, dos desafios futuros enfrentados pelos alunos (Morin, 2006). A habilidade de aprender por conta própria e gerir seu corpo de conhecimento (Rogers, 1977) são os saberes fundamentais para o cidadão e o trabalhador estar inserido em um mundo de mudanças permanentes, incerto, constantemente desafiador (Morin, 2006).

Nos últimos anos, numerosos artigos científicos voltaram-se ao estudo de modelos de aprendizagem alternativos às tradicionais aulas expositivas. Tais estudos acabam por constatar um aumento expressivo no desempenho de alunos que participam de aulas que utilizam algum tipo de aprendizagem ativa, definida como aquela que "envolve estudantes em um processo de aprendizado por meio de atividades, em oposição ao escutar passivamente um especialista, enfatizando raciocínios de alto nível e frequentemente envolvendo trabalho em grupo." (Freeman et al., 2014). Uma metanálise de 225 estudos realizados sobre a eficiência das aulas que envolvem aprendizagem ativa nas disciplinas relativas às ciências, engenharia e matemática (Freeman et al, 2014) demonstrou a necessidade de migrar para a aprendizagem ativa. A melhora de desempenho dos alunos foi constatada em turmas de diversos tamanhos e por variados métodos avaliativos. Outros estudos localizados concluem, da mesma forma, pela maior eficácia da aprendizagem ativa frente às aulas tradicionais, seja na graduação ou no ensino médio (Noora, 2013; Preszler, 2009; Linton, 2014, dentre outros).

Dentre as alternativas existentes, o modelo mais disseminado são aulas na modalidade de ensino híbrido, definido como aquele que mescla aulas tradicionais e novas abordagens tecnológicas, como videoaulas e atividades online (Schiehl \& Gasparini, 2017). É possível alcançar uma maior motivação dos estudantes com uso das didáticas alternativas como as aulas invertidas, sendo um bom caminho criar ferramentas para a disseminação dessas práticas (Araujo et al., 2018) O aprimoramento da didática também conta com o uso crescente dos Recursos Educacionais Abertos, que, por sua disponibilidade e livre acesso, permitem a ampliação de experimento e uso na educação escolar. Contudo, tais alternativas esbarram na dificuldade de pressupor que o acesso a recursos tecnológicos seja suficiente. $\mathrm{O}$ acesso é fundamental, mas também o 
VIII Congresso Brasileiro de Informática na Educação (CBIE 2019)

Anais do XXX Simpósio Brasileiro de Informática na Educação (SBIE 2019)

engajamento dos professores para que os Recursos Educacionais Abertos sejam inseridos no cotidiano escolar. Há, entretanto, uma didática de aprendizagem ativa que se candidata a ser inserida no cotidiano escolar, ao vencer essas barreiras: as Oficinas de Estudo (Mendes, 2012). Em tais aulas, dito de forma breve, os professores apresentam aos alunos o conteúdo a ser trabalho no dia e, por meio de orientações sobre metodologia de estudo e movimentação em sala de aula, leva-os a aprenderem a estudar os conteúdos por conta própria. A característica mais favorável à sua disseminação, contudo, é que não há necessidade de recursos digitais para sua prática, o que geralmente é pressuposto como o caminho natural para trazer aos alunos novas maneiras de aprender (Correia et al., 2018): uma Oficina de Estudo pode ser feita diretamente com livros didáticos impressos ou material entregue aos alunos. Trata-se de uma metodologia de aprendizagem ativa que pode estar presente em qualquer sala de aula, em contraste com o Ensino Híbrido, que requer recursos tecnológicos adicionais

O presente artigo apresenta uma ferramenta web, desenvolvida em pesquisa de pós-doutorado no Programa de Pós-Graduação em Informática na Educação (PGIE) da Universidade Federal do Rio Grande do Sul (UFRGS), para a formação de professores em Oficinas de Estudo. A ideia é tornar disponível um Recurso Educacional Aberto sobre uma didática cuja aplicação não requer uso de tecnologias sofisticadas. $O$ aplicativo, denominado "Aula Leve", permite ao usuário - o professor em formação receber informações teóricas sobre esta didática ativa por meio de vídeos tutoriais, simulação e aplicação da oficina através de um jogo, acesso a um passo a passo como apoio à execução diante dos alunos e, finalmente, o registro e a análise dos resultados da mesma. O aplicativo pode ser acessado por qualquer browser e é responsivo, portanto é, também, amigável com o formato de tela de smartphone e tablets.

\section{Metodologia}

O desenvolvimento do aplicativo se deu pelo Design Science Research, metodologia que objetiva produzir conhecimento sobre a criação de artefatos para resolver problemas específicos dentro de um contexto (Pimentel, Filippo \& Santoro, 2019). O artefato, nesse caso, é o aplicativo Aula Leve desenvolvido na UFRGS com apoio da Secretaria de Educação à Distância (SEAD) e o Núcleo de Apoio Pedagógico à Educação à Distância (NAPEAD) ao longo de 2 anos, entre 2017 e 2018.

O problema a ser resolvido com o artefato é a inserção no cotidiano escolar de uma metodologia de aprendizagem ativa que seja acessível a qualquer contexto escolar podendo, portanto, ser massificada a ponto de contribuir para a melhoria de índices educacionais do país. Identificada a didática de Oficinas de Estudo como metodologia adequada, fez-se necessário estruturar uma formação de curta duração, simples e clara. Para que fosse atingido o objetivo final, isto é a criação de uma ferramenta acessível e com potencial de impacto, foram adotados os seguintes procedimentos:

a) definição das características dos usuários do aplicativo, para que as demais decisões sobre o desenvolvimento do aplicativo fossem adequadas e maximamente efetivas;

b) planejamento da interface instrucional, para que fosse amigável e conseguisse passar as instruções necessárias por um uso adequado de posicionamento dos itens, janelas e design;

c) definição da linguagem de programação; 
VIII Congresso Brasileiro de Informática na Educação (CBIE 2019)

Anais do XXX Simpósio Brasileiro de Informática na Educação (SBIE 2019)

d) elaboração do storyboard da instrução por tutoriais com o detalhamento do passo a passo necessário à execução segura de oficinas de estudo;

e) definição do tipo de ilustração a ser utilizada na elaboração dos tutoriais e no game e as respectivas animações;

f) elaboração das ilustrações e animações;

g) programação do jogo e inserção das ilustrações e animações;

h) construção do banco de dados para registro das informações dos usuários que permitisse o acompanhamento de resultados por meio de questionários.

$\mathrm{O}$ critério para considerar $\mathrm{o}$ artefato válido foi à materialização das funcionalidades descritas. A validação do aplicativo como adequado para a formação de professores se deu pela oferta de um curso de extensão para professores de educação básica. $\mathrm{O}$ curso contou com dois encontros presenciais, destinados à introdução ao aplicativo e à coleta de resultados, sendo o restante das atividades desenvolvida através do aplicativo, a distância. O critério para atestar a formação em Oficinas de Estudo como capaz de levar a aprendizagem ativa ao contexto escolar se deu pela avaliação que os alunos fizeram das aulas ministradas pelos professores participantes do curso de extensão. Considerou-se o resultado positivo nesse último quesito se a avaliação média dos alunos em uma escala de 1 a 5 sobre a satisfação com as Oficinas de Estudo atingisse 4 e se $75 \%$ dos alunos se manifestassem envolvidos com a atividade.

\section{Resultados}

Como resultado da pesquisa-desenvolvimento dispomos da ferramenta web planejada e a satisfação dos critérios acima elencados.

\subsection{Aplicativo Aula Leve}

O aplicativo Aula Leve - Formação gratuita em Oficinas de Estudo (www.ufrgs.br/aulaleve) oferece formação de professores por meio de quatro etapas, cada uma delas representada por um botão que leva a uma página específica (Figura 1): Tutoriais (instruções teóricas por meio de vídeos); Simulação (jogo que coloca em prática o que os tutoriais instruem); Passo a Passo (resumo dos passos de uma Oficina) e; Minhas Oficinas (registro de Oficinas).

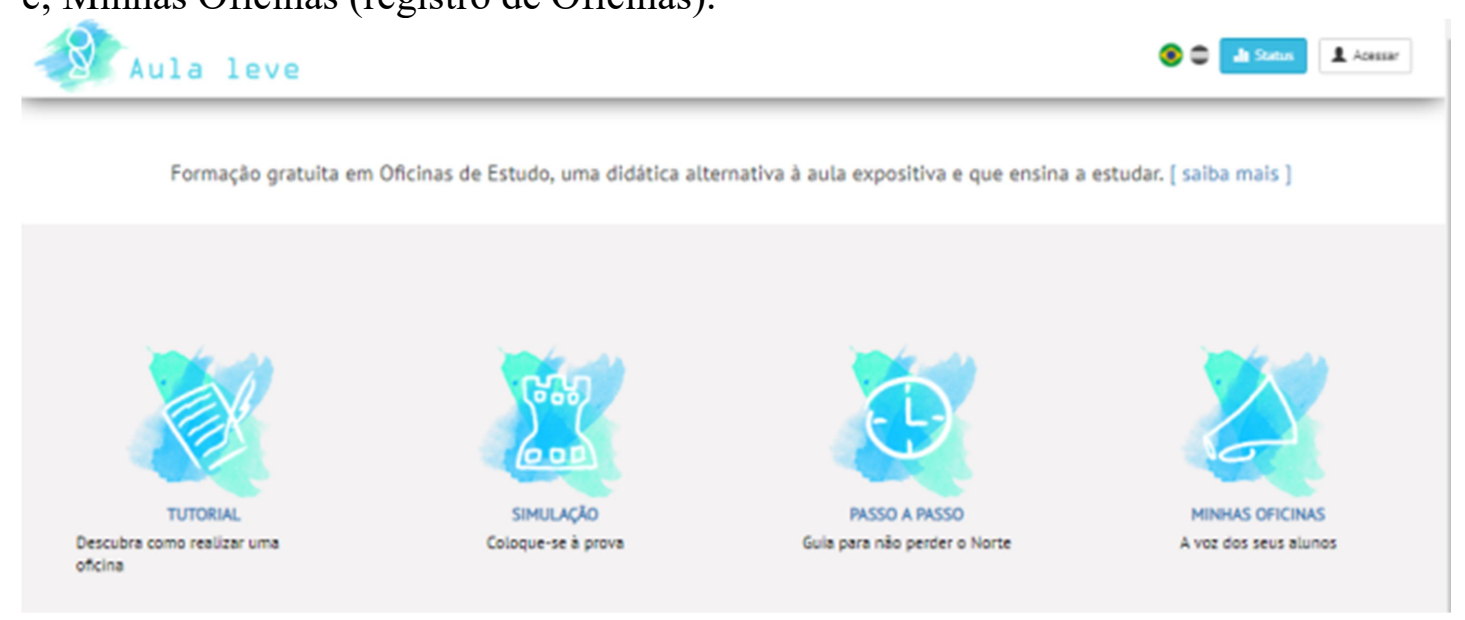

Figura 1 - Página inicial com os botões que levam às páginas correspondentes 
VIII Congresso Brasileiro de Informática na Educação (CBIE 2019)

Anais do XXX Simpósio Brasileiro de Informática na Educação (SBIE 2019)

O usuário pode se cadastrar clicando em um botão na barra superior e acompanhar o progresso de sua formação por meio de uma barra de status. Quando assistir $100 \%$ dos vídeos, alcançar um score mínimo 8,0 na simulação e obtiver ao menos $80 \%$ de aprovação nas Oficinas de Estudo registradas e realizadas, sua formação é considerada concluída.

O Botão "Tutoriais" leva à página correspondente (www.ufrgs.br/aulaleve/tutorial) e apresenta, através de oito vídeos tutoriais (com duração total 30 minutos), todos os conteúdos necessários para o usuário ter condições de ministrar uma aula em Oficina de Estudo. Os vídeos são: Apresentação, Preparação, Introdução (às Oficinas de Estudo), Etapa 1 - Leitura Panorâmica, Etapa 2 Marcar/Sublinhar, Etapa 3 - Anotações, Etapa 4 - Exercícios e Fechamento. Tais vídeos mesclam gravações em vídeo com um narrador, no caso o autor do projeto, ilustrações e animações. Além dos vídeos, a seção conta com esclarecimento de questões frequentes na barra "Desafios". (Figura 2)

1 - Apresentação

\begin{tabular}{|l|}
\hline Introdução (02:05) \\
\hline Etapa 1 - Leitura Panorâmica (03:01) \\
\hline Etapa 2 - Marcar/Sublinhar (05:40) \\
\hline Etapa 3 - Anotaçòes (03:15) \\
\hline Etapa 4 - Exercícios (02:49) \\
\hline Fechamento (03:42) \\
\hline
\end{tabular}

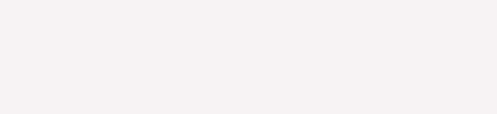

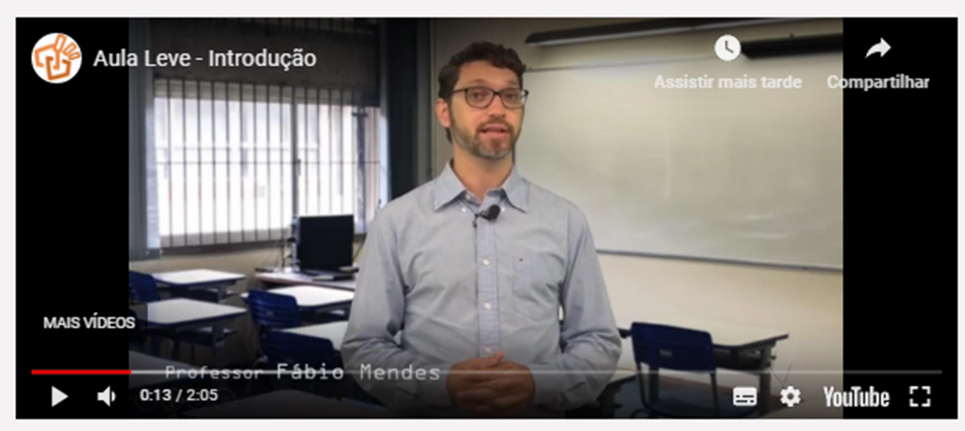

\section{Desafios}

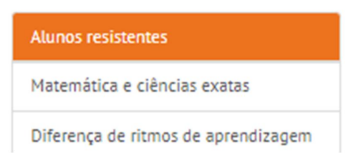

Alguns alunos simplesmente resistem à idéia de terem um papel mais ativo no aprendizado. Não querem participar e, ainda, podem propositadamente atrapalhar os colegas.

Nas Oficinas de Estudo, essa resistência é quebrada com dois recursos: movimentação do professor e renetida intervencão individual oferecendo aiuda $e$ incentivo a executar as etanas devido a sua

Figura 2 - Página "Tutoriais" com exemplo de vídeo instrucional

O botão seguinte na página inicial, e que corresponde ao segundo momento da formação disponibilizada, leva a uma página Simulação (Figura 4) com um jogo que simula a aplicação de uma Oficina de Estudo (www.ufrgs.br/aulaleve/simulacao $)$. O jogo, desenvolvido a várias mãos, apresenta uma personagem principal, a Prof ${ }^{\mathrm{a}}$ Amanda, e as decisões necessárias à condução bem sucedida de uma Oficina de Estudo (Figura 3). Opções são apresentadas: as corretas pontuam positivamente e levam a uma animação ou à questão seguinte; as incorretas pontuam negativamente e justificam o motivo de não ser uma boa escolha. O jogo se encerra com a apresentação da pontuação do usuário, de 0 a 10,0. Foi definida a pontuação mínima 8,0 como meta para, então, experimentar concretamente a realização de uma Oficina de Estudo com seus alunos regulares. 

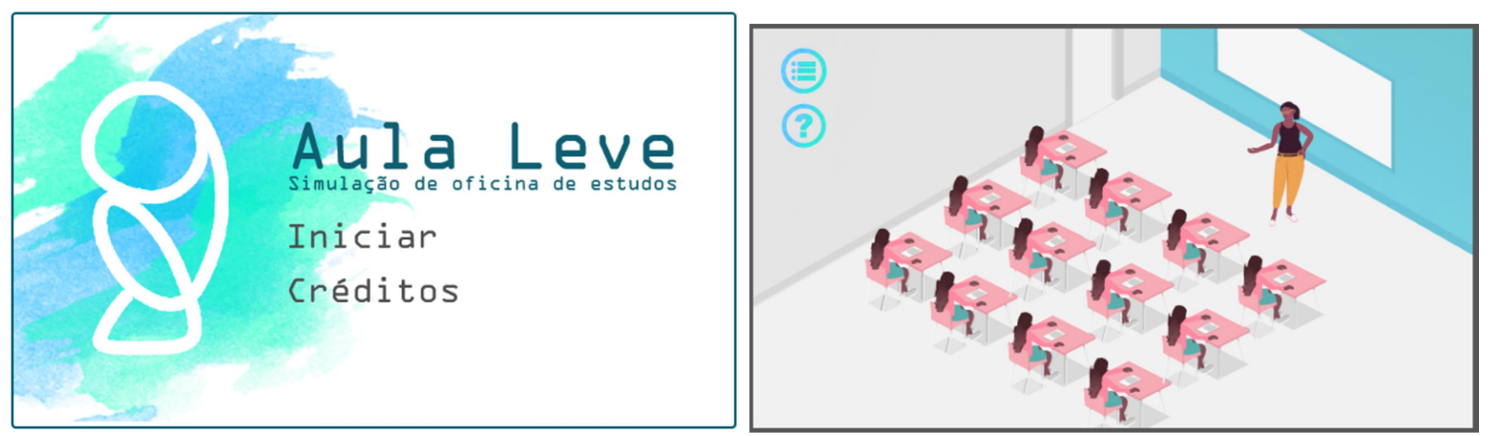

Figura 3 - Página Simulação com a capa do jogo a esquerda e imagens do jogo com a personagem em uma situação especí fica em uma Oficina de Estudo.

A página Passo a Passo (www.ufrgs.br/aulaleve/oficina), acessada pelo botão de mesmo nome, apresenta uma lista no formato sanfona com todos os passos necessários à execução de uma Oficina de Estudo (Figura 4). A intenção é que essa lista seja acessada pelo professor durante a realização da atividade, servindo como um guia. Cada um dos itens conta com uma explicação adicional que aparece em Tooltip. Abaixo da lista, um cronômetro é disponibilizado para ajudar o professor a se orientar dentro do tempo das atividades.

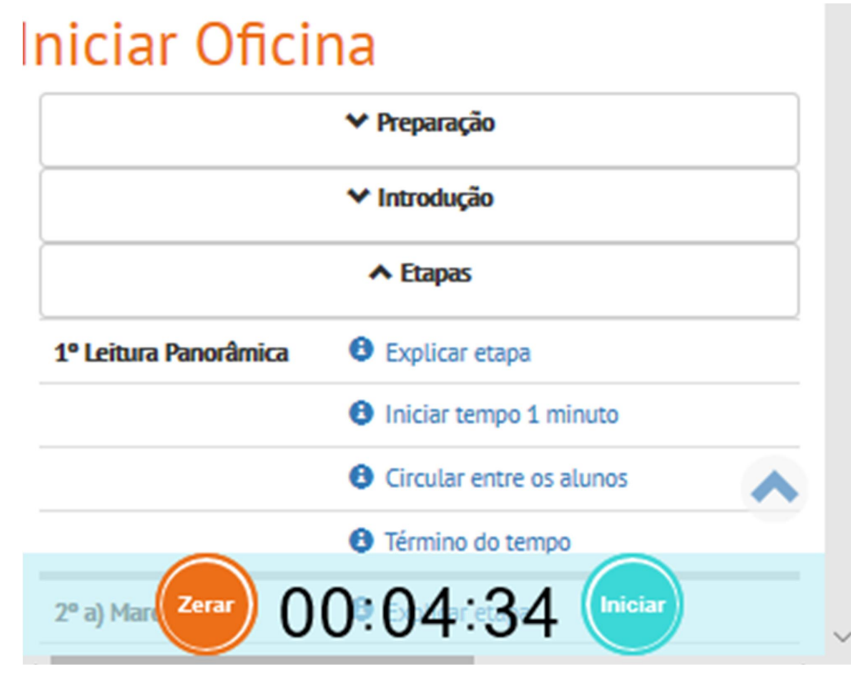

Figura 4 - Página Passo a Passo em formato responsivo

O último botão, Minhas Oficinas (www.ufrgs.br/aulaleve/questionario/lista), leva à página que possibilita ao usuário o acompanhamento dos resultados concretos de sua formação (Figura 5). Isso é feito por meio do cadastro de oficinas e preenchimento de fichas de avaliação pelos alunos. A página apresenta um quadro que resume as estatísticas principais resultantes do total das oficinas já cadastradas, exibidas em uma lista abaixo. Além disso, é possível acessar o resultado de cada Oficina, clicando no botão próprio, para que seja exibido um breve relatório com gráficos relativos à aprovação e ao envolvimento dos alunos, além de suas respostas qualitativas (Figura 6). 
VIII Congresso Brasileiro de Informática na Educação (CBIE 2019)

Anais do XXX Simpósio Brasileiro de Informática na Educação (SBIE 2019)

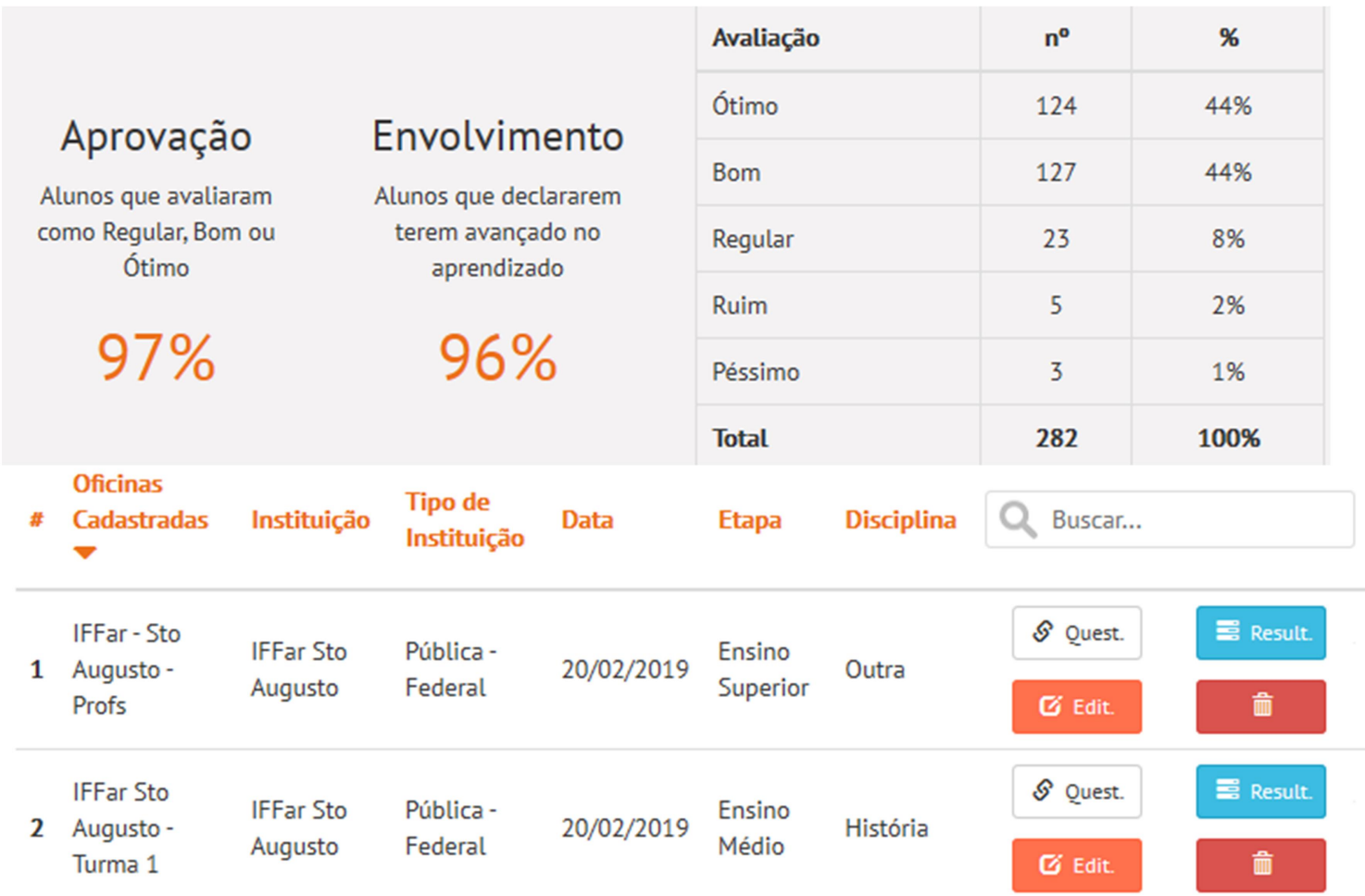

Figura 5 - Página Minhas Oficinas, com resumo dos resultados globais do usuário a partir avaliações realizadas pelos alunos das Oficinas de Estudo cadastradas.

Resultados de: IFFar Sto Augusto Turma 3

\begin{tabular}{ll}
\hline Disciplina: & História \\
\hline Etapa: & Ensino Médio \\
\hline Nome da Instituição: & IFFar Sto Augusto \\
\hline Gidade: & Santo Augusto / RS
\end{tabular}

Inserir Respostas Manualmente

Avaliação

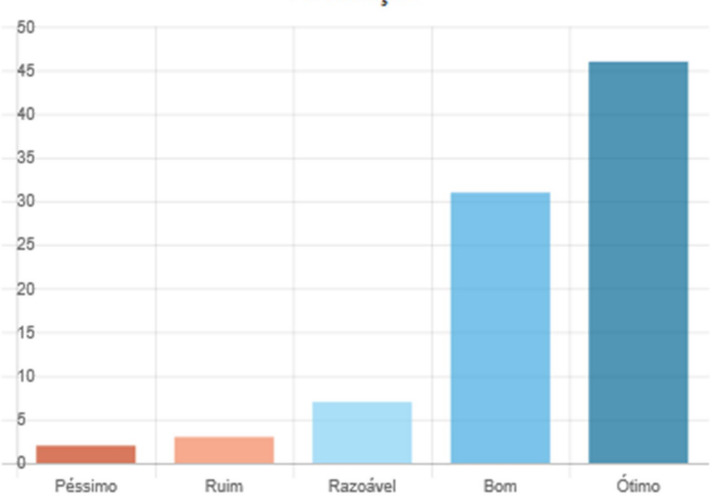

Comentários dos Alunos

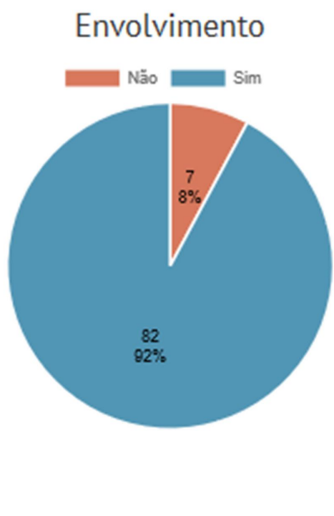

ótimo método!

legal :)

Figura 6 - Resultados de uma Oficina de Estudo cadastrada. 
VIII Congresso Brasileiro de Informática na Educação (CBIE 2019)

Anais do XXX Simpósio Brasileiro de Informática na Educação (SBIE 2019)

\subsection{Curso de extensão e resultados}

Ofertamos um curso de extensão com o objetivo de avaliar se o aplicativo Aula Leve, de fato, era funcional, se permitia a formação de professores e se as aulas em Oficinas de Estudo por eles ministradas atingiam os objetivos da aprendizagem ativa. $\mathrm{O}$ curso, voltado para professores da Educação Básica, contou com 2 encontros presenciais (04/02 - Introdução à formação e 27/02 - Resultados e Fechamento), as atividades online no aplicativo e o registro de Oficinas de Estudo ministradas. Para auferir os resultados foram observados os registros dos professores de suas aulas e um longo questionário de feedback sobre o curso e o aplicativo.

Dos 27 professores inscritos para 30 vagas, 11 realizaram a formação. Todos os participantes mostraram-se satisfeitos com a formação proporcionada (em uma escala de 0-5, foram 6 avaliações 5 e 5 avaliações 4), destacando associar o aplicativo à simplicidade, clareza e dinamismo. Segue um exemplo:

Elas dinamizam a forma do aluno aprender, sendo que este se torna responsável pela busca do conhecimento. O professor torna-se um mediador e não um transmissor de conteúdo. As orientações de condução da atividade em casos de conversas e desatenções são úteis, como as outras sugestões. A forma diferenciada de apresentação do conteúdo é atraente, coloca o docente em movimento, e também o torna um mediador do conhecimento.

Segundo as indicações dos professores que testaram a ferramenta, pode-se constatar que esta foi válida em relação às suas funcionalidades e que atingiu seu objetivo de formação docente.

Em relação às Oficinas de Estudo ministradas por tais professores serem capazes de levar a aprendizagem ativa ao contexto escolar, foi considerado o feedback dos alunos em relação às aulas que receberam dos professores participantes. Foram realizadas 22 Oficinas de Estudo em 12 instituições de ensino (abrangendo o ensino público municipal, estadual e federal, assim como o particular) com 451 questionários de avaliação colhidos de alunos de ensino fundamental, médio e superior de diversas disciplinas. Os resultados (Figura 8) foram positivos ao atingirem as nossas metas de avaliação, ou seja, a média de 4,27 para a aceitação da atividade e o envolvimento de $75 \%$ dos alunos que percebem a melhoria do conhecimento sobre o conteúdo após a realização da oficina. Registramos que tais resultados superaram nossas expectativas.

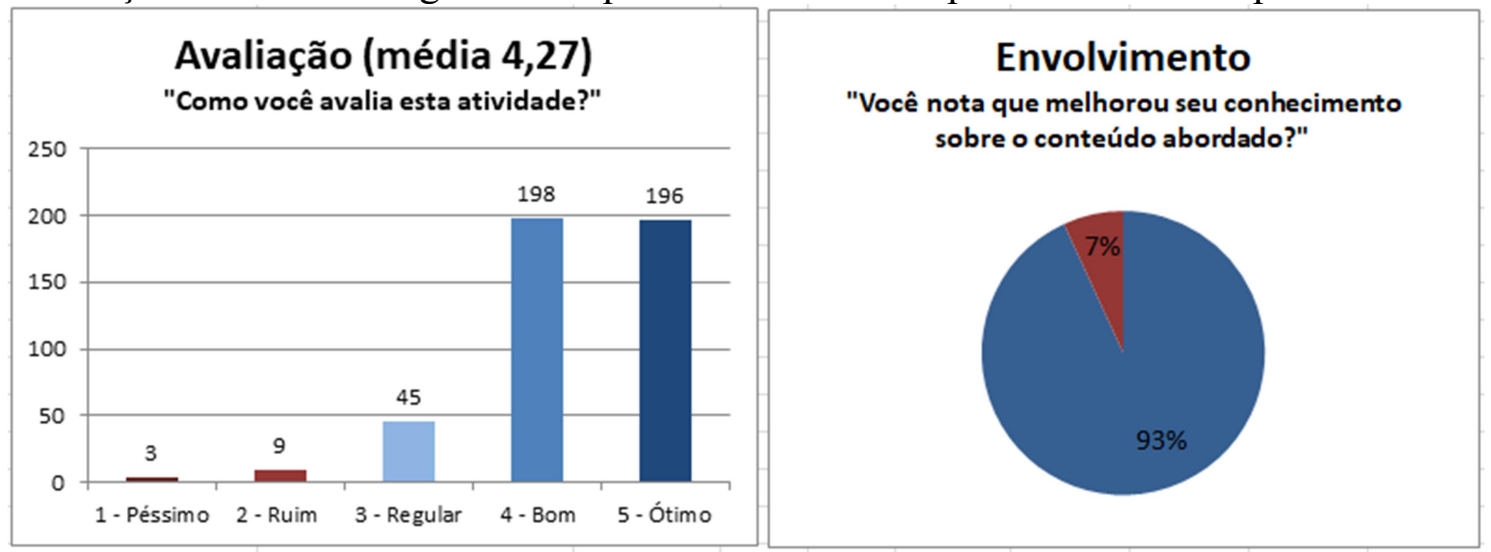

Figura 8 - Avaliação e envolvimento de alunos participantes das Oficinas de Estudo ministradas por professores formados no curso de extensão. 
VIII Congresso Brasileiro de Informática na Educação (CBIE 2019)

Anais do XXX Simpósio Brasileiro de Informática na Educação (SBIE 2019)

\section{Considerações finais}

As metodologias de aprendizagem ativas atendem melhor ao desenvolvimento de raciocínios de alto nível e a melhoria no desempenho dos alunos se comparadas às aulas tradicionais.

O aplicativo Aula Leve tem em vista inserir no cotidiano escolar uma metodologia de aprendizagem ativa acessível a qualquer contexto escolar. Oferecemos um curso de formação de professores em Oficinas de Estudo para seu posterior desenvolvimento e testagem em sala de aula com seus próprios alunos.

O retorno dos professores, que testaram a ferramenta, validaram sua funcionalidade e capacidade de fornecer formação docente em aprendizagem ativa. A avaliação e o envolvimento positivos dos alunos superaram nossas expectativas. Tal fato convida à disseminação da ferramenta. $\mathrm{O}$ artefato responde de forma positiva à criação de um Recurso Educacional Aberto com uma didática diferenciada e que não requer aparatos tecnológicos sofisticados para a sua aplicação. O Aula Leve ao facilitar a formação dos professores sobre uma metodologia ativa e ao ser aplicada junto os alunos com avaliação positiva, cumpre seu objetivo maior que é o envolvimento dos alunos com a própria aprendizagem. Temos em vista realizar mais estudos sobre o efeito da formação do Aula Leve no desempenho escolar de alunos da Educação Básica

\section{Referências}

Araújo P. T.; Carvalho, W. C.; Veras, N. L., Castro Filho, J. A. (2018) “Aprendizagem Adaptativa em Aulas Invertidas de Sistemas Distribuídos: um estudo de caso apoiado no GSuite. In.: Anais do SBIE. Disponível em: < http://www.brie.org/pub/index.php/sbie/article/view/7989/5683 > . Acesso em: 05 Jul 2019.

Arnold, J. and J. Jalles (2014), "Dividing the Pie in Brazil: Income Distribution, Social Policies and the New Middle Class". In.: OECD Economics Department Working Papers, No. 1105, OECD Publishing. <http://dx.doi.org/10.1787/5jzb6w1rt99p-en>

Bauman, Z. (2007) Tempos líquidos. São Paulo: Zahar, 2007.

Carvalho, M. J.; Neves, B.; Melo, R. (2016). "Plataforma CultivEduca". In.: Anais do CBIE. Disponível em: www.br-ie.org/pub/index.php/wcbie/article/ download/6919/4793>. Acesso em: 29/08/2019. 2019.

Correia, K. S. M; Fook, K. D.; Sá, E. J. V. (2018). "LogEasy++: Uma ferramenta para ensino e aprendizagem personalizável utilizando Gamificação”. In.: Anais do SBIE. Disponível em: < http://www.brie.org/pub/index.php/sbie/article/view/8014/5708>. Acesso em: 05 Jul. 2019.

Foresti, A.; Teixeira, A. C. (2012) "Proposta de um conceito de aprendizagem para a era digital." In.: RELATEC: Revista Latinoamericana de Tecnología Educativa, 2012, Vol.11(2), pp.55-68

Freeman, S.; Eddy, S. et alles. (2014) "Active learning increases student performance in science, engeneering and mathematics." In. Proceedings of the National Academy of Sciences (USA), v. 111, n. 23, junho, 2014. (Disponível em $<$ http://www.pnas.org/content/111/ 23/8410.full?sid=e90446fa-90c9-4bf8-af8e02bb4bbcdc43>, acessado em 15/01/2016) 
VIII Congresso Brasileiro de Informática na Educação (CBIE 2019)

Anais do XXX Simpósio Brasileiro de Informática na Educação (SBIE 2019)

Gesser, V. (2012) "Novas tecnologias e educação superior: Avanços, desdobramentos, Implicações e Limites para a qualidade da aprendizagem." In.: IE Comunicaciones: Revista Iberoamericana de Informática Educativa, 2012, Issue 16, pp.23-31

Linton, D.; Farmer, J.; Peterson, E. (2012) "Is peer interaction necessary for optimal active learning”. In.: CBE - Life, Science, Education. v. 13, 243-252, verão 2014.

Mendes, F. R. (2012) A nova sala de aula. Porto Alegre: Autonomia, 2012.

Mendes, F. R. (2019) Aplicativo Aula Leve. UFRGS, 2019. Disponível em < http://www.ufrgs.br/aulaleve > Acesso em 05 Abr 2019.

Morin, E. (2006) Os sete saberes necessários à educação do futuro. São Paulo: Cortez, 2006.

Morin, E.; Ciurana, E-R.; Motta, R. D. (2007) Educar na era planetária: o pensamento complexo como método de aprendizagem pelo erro e incerteza humana. São Paulo: Cortez, 2007.

Noora, H; Mcknight, K. et alles. (2013) A Rewiew On Flipped Learning. Pearson, 2013. (Disponível em <http://www.flippedlearning.org/review>, acessado em 15/01/2016).

OCDE. (2014) "What 15-year-olds know and what they can do with what they know". In.: PISA 2012 Results in Focus. OECD Publishing, 2014, (Disponível em http://www.oecd.org/pisa/keyfindings/pisa-2012-results-overview.pdf ， acessado em 03/04/2016)

OECD. (2015) Education and skills: developing skills and education for growth. OECD Publishing, 2015. (Disponível em http://www.oecd.org/education/brazildeveloping-skills-and-education-for-growth.pdf, acesso em 03/04/2016)

Perrenoud, Philippe (et al.). (2007) As competências para ensinar no século XXI : a formação dos professores e o desafio da avaliação. Porto Alegre: Artmed, 2007.

Pimentel, M.; Felippo, D.; Santoro, F. M. (2019) "Design Science Research: fazendo pesquisas científicas rigorosas atreladas ao desenvolvimento de artefatos computacionais projetados para a educação." In: Jaques, P. A.; Pimentel, M.; Siqueira S; Bittencourt, I. (Org.) Metodologia de Pesquisa em Informática na Educação: Concepção da Pesquisa. Porto Alegre: SBC, 2019. (Série Metodologia de Pesquisa em Informática na Educação, v. 1) Disponível em: $<$ https://metodologia.ceie-br.org/livro-1/>.

Preszler, R. (2009) "Replacing lecture with peer-led workshops improves student learning”. In.: CBE-Life, Science, Education. v. 8, 182-92, outono 2009.

Rogers, C. (1977) Carl Rogers on Personal Power. Nova York: Delacorte, 1977.

Schiehl, E. P.; Gasparini, I. (2017). "Modelos de Ensino Híbrido: Um Mapeamento Sistemático da Literatura." In: Anais do SBIE. Disponível em: < http://www.brie.org/pub/index.php/sbie/article/view/7529/5325>. Acesso em: 07 Jul. 2019.

Unicef. (2014) 10 desafios do ensino médio no Brasil. Brasília: Unicef, 2014 